\title{
La influencia de Saadiá Gaón en el Comentario de Abraham ibn Ezrá al libro de Job
}

\author{
Mariano Gómez ArandA* \\ Instituto de Filología - CSIC, Madrid
}

\section{INTRODUCCIÓN}

Saadiá Gaón (882-942) es uno de los pioneros en la utilización de métodos científicos y racionales en la explicación de la Biblia; en sus comentarios utiliza sus conocimientos en filología comparada, gramática, lexicografía, filosofía y otras disciplinas científicas para interpretar el texto bíblico. Su metodología científica tuvo una gran influencia en los comentaristas y gramáticos de Sefarad, como Dunaš ben Labrat, Yoná ibn Yanaḥ, Ishaq ibn Gayyat y el propio Ibn Ezrá, entre otros.

Abraham ibn Ezrá (1089-1164) cita a Saadiá Gaón más de doscientas veces en sus comentarios a la Biblia ${ }^{1} \mathrm{y}$ también encontramos referencias a él en el resto de sus obras; incluso una de ellas, conocida con el nombre de Sefat Yéter, está dedicada a la defensa de Saadiá Gaón contra las críticas dirigidas a él por un tal R. Adonim Haleví, que algunos han identificado con Dunaš ben Labrat ${ }^{2}$.

\footnotetext{
*aranda@filol.csic.es
}

${ }^{1}$ Sobre la influencia de Saadiá Gaón en el comentario a la Torá de Ibn Ezrá, véase A. BROMBERG, «Influence of Saadia on Abraham Ibn Ezra» (en hebreo), Talpioth 9 (1970) págs. 761-784.

2 Abraham IBN EzRA, Sephat Jether. Beleuchtung dunkler Bibelstellen, insbesondere zur Vertheidigung R. Saadia's gegen R. Adonim Levita, genannt Dunasch ben Librat, von R. Abraham Ibn-Esra. Kritisch bearbeitet und mit einem Commentar nebst Einleitung versehen von Dr. G. H. Lippmann, Frankfurt am Main 1843 (en adelante Sefat Yéter). Véase también Y. OsHRI (ed.), ספר ההגנה על רב סעדיה גאון המכונה שפת יתר. M.A. Thesis, Bar Ilan University 1988. Sobre el autor de las críticas contra Saadiá Gaón, véase A. SÁENz-BADILlos, «Sobre el autor de las Tešubot 'al Se 'adyah», en Exilio y Diáspora. Estudios sobre la historia del pueblo judio en homenaje al Profesor Haim Beinart. Ed. A. Mirsky, A. Grossman and Y. Kaplan, Jerusalem 1991, págs. 26-43. 
En la introducción al Séfer Moznáyim, Ibn Ezrá se refiere al «gaón R. Saadia, de la ciudad de Pitom» como «el primero de cuantos tomaron la palabra en cualquier lugar» ${ }^{3}$. La actitud que Ibn Ezrá muestra en sus obras hacia el Gaón es muy diversa y se extiende desde la admiración y el respeto hasta el rechazo más absoluto ${ }^{4}$.

En este artículo analizaré las influencias de Saadiá Gaón en el comentario de Abraham ibn Ezrá al libro de Job con el fin de evaluar el impacto que tuvieron los puntos de vista del Gaón hacia este libro bíblico en la metodología exegética de Ibn Ezrá 5 .

El comentario de Saadiá Gaón a Job supuso una importante novedad en su época en la exégesis de este libro bíblico, porque, frente a las interpretaciones de carácter homilético que encontramos en el Talmud y los midrašim ${ }^{6}$, él aportaba una perspectiva científica, que se basaba en las reglas gramaticales, los principios de la lingüística comparada y la filosofía de su tiempo ${ }^{7}$. Su comentario,

\footnotetext{
${ }^{3}$ Abraham IBn Ezra, Sefer Moznayim. Introducción (en castellano y en inglés), edición crítica del texto hebreo y versión castellana de L. Jiménez Patón. Revisada, completada y reelaborada por A. Sáenz-Badillos, Córdoba 2002, págs. 4* y 107.

${ }^{4}$ Y. Avishur, «The Attitude of R. Avraham Ibn Ezra to the Translation and Commentary of R. Saadia Gaon», Abraham ibn Ezra y su tiempo. Actas del Simposio Internacional. F. Díaz Esteban, ed. Madrid 1990, págs. 17-24.

${ }^{5}$ Para la edición de este comentario, véase M. GómEz ARANDA, El comentario de Abraham ibn Ezra al libro de Job. Edición crítica, traducción y estudio introductorio, Madrid 2004 (en adelante Com. $J o b)$.

${ }^{6}$ Para una evaluación de la exégesis rabínica y de Raší sobre el libro de Job, véase M. EisEmanN, Iyob. Job. A New Translation with a Commentary Anthologized from Talmudic, Midrashic and Rabbinic Sources, New York 1994, y A. J. Rosennerg, Job. A New English Translation. Translation of the Text, Rashi, and Other Commentaries, New York 1995. Véase también L. GinzBeRG, The Legends of the Jews, vol. II, Philadelphia 1946, págs. 225-242 y vol. V, Philadelphia 1947, págs. 381-390. Las interpretaciones midrásicas sobre este libro fueron recogidas en S. A. WERTHEIMER (ed.), Baté Midrašot. Midraš Iyyob, Jerusalem 1968, vol. 2, págs. 151-186.

${ }^{7}$ Para la edición de este comentario, véase Y. KAFAH (ed.), איוב עם תרגום ופירוש הגאון רבנו סעדיה בן Jerusalem 1972 (en adelante, KAFAH); para una traducción al inglés y estudio de la obra, véase The Book of Theodicy. Translation and Commentary on the Book of Job by Saadiah Ben Joseph Al-Fayyumi. Translated from the Arabic with a Philosophic Commentary by L. E. Goodman, New Haven-London 1988 (en adelante Theodicy). El estudio más reciente sobre la exégesis de Saadiá Gaón al libro de Job se puede encontrar en R. EIsEN, The Book of Job in Medieval Jewish Philosophy, Oxford 2004, págs. 17-41; véase también del mismo autor «Job as a Symbol of Israel in the Thought of Sa'adiah Ga'on», Daat 41 (1998) V-XXV. Véase también E. I. J. RosentHAL, «Saadya's Exegesis of the Book of Job», Saadya Studies. Edited by E. I. J. Rosenthal, Manchester 1943, págs. 177-205; reimpreso en Studia Semitica, Vol. I: Jewish Themes, Cambridge 1971, págs. 97-125; L. E. Goodman, «Saadia Gaon's Interpretive Technique in Translating the Book of Job», D. M. Goldenberg (ed.), 
escrito en judeo-árabe, va acompañado de una traducción a esta lengua del texto hebreo. Saadiá Gaón aborda el tema central del libro, el problema del mal en el mundo y el sufrimiento de los inocentes, y trata de dar una respuesta utilizando como argumento que Dios es infinitamente justo y que el ser humano es incapaz de conocer la manera de actuar de la Divina Providencia. El sufrimiento del justo y honrado Job no es un castigo por sus pecados, sino una manera de poner a prueba su fe. Saadiá pone un énfasis especial a la hora de mostrar la naturaleza y los atributos de Dios para justificar sus actuaciones en el mundo; es decir, se centra en los aspectos teológicos del texto.

\section{Citas de SaAdiá Gaón en el comentario de Ibn Ezrá}

En su explicación de Jb 1,6, Saadiá Gaón interpretó que la figura de Satán, mencionada en el versículo, era en realidad un ser humano que sentía envidia de Dios, no un ángel; su argumento estaba basado en el hecho de que la palabra 'Satán' se utiliza en la Biblia con el sentido de 'adversario' u 'oponente', tal como aparece en $1 \mathrm{Re}$ 11,14.23; Zac 3,1; 3,2; Sal 38,21; etc. Además, se oponía a la interpretación angélica de Satán argumentando que «todos los monoteístas coinciden en que el Creador hizo a sus ángeles, que son los que le sirven, sabiendo que no le desobedecerían» y afirmando que considerar que un ángel puede rebelarse contra Dios va en contra de este principio básico. Añade Saadiá otro argumento en contra de la identificación de Satán como ángel, basándose en la teoría filosófica de las tres facultades del alma, una de las cuales es la que produce la ira; debido a que la envidia es un tipo de ira y que esta facultad es propia de los animales, no se puede aplicar a los seres celestiales ${ }^{8}$. Con estas interpretaciones, Saadiá Gaón está intentando humanizar la historia de Job considerando tanto a los hijos de Elohim como al propio Satán como seres humanos, tratando de evitar las conexiones mitológicas entre Dios y el mal, con el fin de presentar desde una perspectiva más racionalista el contexto en el que se desarrollan los acontecimientos del libro bíblico ${ }^{9}$.

Translation of Scripture, Philadelphia 1990, págs. 47-76 y su «Saadia Gaon on the Human Condition», JQR 67 (1976) 23-29. Agradezco a M. a A. Gallego su ayuda para la traducción de los textos de Saadiá.

${ }^{8}$ KAFAH, págs. 26-27 y Theodicy, págs. 154-155.

${ }^{9}$ Goodman opina que Saadiá Gaón pretende de esta manera oponerse a las interpretaciones midrásicas, cristianas y musulmanas sobre el libro de Job, que consideran a Satán como un ángel rebelde; según Goodman, a Saadiá esta idea podría suponer un peligro para el monoteísmo y mucho más cuando estaba asociada con las doctrinas gnósticas o maniqueas sobre los seres celestiales; vid. Theodicy, pág. 167, nota 28. 
Pero Saadiá Gaón era consciente de que otros autores consideraban a Satán como un ángel y afirma que quienes así lo interpretaron se basaron en las palabras que Dios le dirige: «todo lo que tiene está en tus manos» $(\mathrm{Jb} 1,12)$ y «respétale la vida» (Jb 2,6). Para contradecir esta opinión, Saadiá trata de evitar aquellas interpretaciones que implican que el ángel rebelde Satán es el que produce los males a Job. Para ello comienza diciendo que la palabra T en la Biblia, que literalmente significa 'mano' y que se suele interpretar en el sentido de 'poder', se utiliza también con el significado de 'deseo' o 'intención', como por ejemplo en «iha estado la intención de (דָָדָ) Joab contigo en esto?» (2 Sam 14,19); es decir, que las palabras de Dios «todo lo que tiene está en tus manos» $(\mathrm{Jb} 1,12)$ no quieren decir que todas sus posesiones estén bajo el poder de Satán, sino que significan «todo lo que tiene es tu deseo» ${ }^{10}$. Según este sentido, Satán no tiene la capacidad de producir desgracias a Job, sino que es Dios el que puede disponer de su destino ${ }^{11}$. Este sentido implica también que el ser humano Satán siente envidia de las posesiones de Job. Con respecto a la frase «respétale la vida» (Jb 2,6), Saadiá interpreta que lo que Dios le dice al adversario es lo siguiente: «ten en cuenta su alma, es decir, no me pidas que le ponga a prueba su alma, porque sólo se puede poner a prueba cuando el cuerpo y el alma están juntos, pero no cuando se separan»y añade que el significado de שמר en este caso es similar a השמר 'tener cuidado', 'tener en cuenta' o 'abstenerse de hacer algo' ${ }^{12}$. El argumento de Saadiá en este caso también trata de evitar el significado más obvio del versículo porque implicaría que el Satán tiene poder para decidir sobre la vida o la muerte de Job; contra esta interpretación reacciona Saadiá explicando que lo que Dios le está pidiendo al ser humano adversario de Job es que tenga cuidado y se abstenga de solicitarle que le quite la vida a Job, porque Dios no está dispuesto a llegar tan lejos ${ }^{13}$.

Abraham Ibn Ezrá resume la argumentación de Saadiá en su comentario a Jb 1,6 ${ }^{14}$. Sus primeras críticas van dirigidas en contra de la consideración de Saadiá de que la palabra 'Satán' solo se aplica a los seres humanos y cita como prueba el versículo «se colocó el ángel de Dios en el camino como un Satán» (Nú 22,22), donde claramente aparece un ángel divino con dicha denominación. También menciona la actuación del ángel Miguel, que lucha contra

\footnotetext{
${ }^{10}$ KafaH, págs. 28-29 y Theodicy, pág. 156.

${ }^{11}$ EISEN, The Book of Job, pág. 25.

${ }^{12}$ KafaH, pág. 37 y Theodicy, págs. 173-174.

${ }^{13}$ Véase una interpretación muy similar en EISEN, The Book of Job, pág. 25.

${ }^{14}$ Com.Job, pág. 8*, 10-12.
} 
sus adversarios en defensa de Israel, tal como aparece en Da 10,21, y que Ibn Ezrá interpreta en el contexto de las intervenciones de los ángeles protectores de sus naciones correspondientes en las luchas de los imperios ${ }^{15}$. Utilizando su lenguaje críptico habitual, Ibn Ezrá añade que «para aclarar estos misterios no bastaría con un libro, pero el que entienda el secreto de las disposiciones de los ejércitos celestes y el cambio de sus influencias según los movimientos conocerá el origen de Satán y sabrá que es un ángel»; es decir, relaciona la figura de Satán como ángel con la influencia de los astros sobre los seres terrenales. La idea de que los ángeles están encargados de mover los astros de manera que influyan en el mundo terrenal es típica de Ibn Ezrá y aparece con frecuencia en sus obras ${ }^{16}$. Al hacer esta afirmación concreta a propósito de Satán, Ibn Ezrá está insinuando que se trata de un ángel concreto encargado de mover determinados astros de manera que influyan negativamente en el propio Job.

Al igual que Saadiá Gaón, Ibn Ezrá está buscando una explicación racional a la controvertida figura de Satán, aunque, a diferencia de aquel, recurre a los principios de la astrología de la época para encontrar sus argumentos. En el Sefat Yéter, Ibn Ezrá trató de disculpar la interpretación de Saadiá, afirmando que el Gaón no fue capaz de entender las enormes dificultades para entender el misterio de las relaciones entre los ángeles y los astros ${ }^{17}$.

También en su comentario a Jb 1,6, menciona Ibn Ezrá otra interpretación de Saadiá sobre las que no expresa ninguna opinión, aunque, por otras referencias, podemos suponer que Ibn Ezrá no la aceptaba. En su propósito de contextualizar la historia, Saadiá Gaón consideró que la referencia en Jb 1,1 al país de Us significaba que los hechos relatados en el libro ocurrieron en la propia tierra de Uz, hijo de Nahor y sobrino de Abraham ${ }^{18}$. Para Ibn Ezrá, en cambio, Us es uno de los descendientes de Esaú, que es Edom según Gé 36,1. Para justificar

${ }^{15}$ Véase el comentario corto a Da 10,13 y sigs. en Abraham IBN EzRA, The Short Commentary on Daniel. A Critical Edition with an Introduction, Super-Commentary, Indices and Appendices by A. Mondshine (en hebreo). M.A. Thesis, Department of Bible, Bar-Ilan University, RamatGan 1977, págs. 63-64 y notas en págs. 178-179. Sobre las conexiones entre ángeles protectores y las naciones de la tierra, véase S. Sela (en hebreo), Astrology and Biblical Exegesis in Abraham Ibn Ezra's Thought (en hebreo), Ramat Gan 1999, págs. 134-135.

${ }^{16}$ M. Gómez Aranda, «Aspectos científicos en el Comentario de Abraham ibn Ezra al libro de Job», Henoch 23 (2001) 81-96: 82-83.

${ }^{17}$ Sefat Yéter, pág. $19 b$.

${ }^{18}$ KAFAH, pág. 23 y Theodicy, pág. 151. En Gé 22,21 se dice que Nahor, hermano de Abraham, tuvo un hijo llamado Us de quien, según esta interpretación, nació Job. Así también lo interpretó Raší; véase Peruš, $i b$. 
su argumento cita «ialégrate y regocíjate, hija de Edom, que habitas en el país de Us!» (La 4,21), donde aparece la conexión Us-Edom-Esaú ${ }^{19}$. A pesar de las diferencias, Ibn Ezrá coincide con Saadiá en el hecho de enfatizar que Job no pertenecía al pueblo de Israel, aunque, tal como indica Saadiá en su comentario, hubo exegetas que trataron de encontrar alguna manera de justificar la pertenencia de Job al pueblo judío ${ }^{20}$.

En su comentario a Jb 3,23, Ibn Ezrá explica que el hombre que aparece en dicho versículo sobre el cual se dice «cuyo camino está oculto y a quien Dios cercó» es uno de «los que esperan la muerte» mencionados en el versículo 21. Además añade que la expresión «a quien Dios cercó» significa que «lo encerró» para dejar claro que la acción de Dios consiste en encerrar al hombre para que de esta manera su camino esté oculto ${ }^{21}$. Después dice Ibn Ezrá lo siguiente: «El Gaón R. Saadiá lo interpretó en sentido contrario y dijo que significa: no hay necesidad de vivir sino para el hombre cuyo camino está oculto, aunque ni siquiera disfruta con la comida». ¿Por qué sostiene Ibn Ezrá que Saadiá lo interpretó en un sentido opuesto al suyo? El Gaón traduce Jb 3,23 como una continuación de $\mathrm{Jb}$ 3,20 y dice así «[¿por qué dará Él luz] a un hombre al que se le han ocultado sus asuntos porque han sido cercados por Dios, dejándolo a él fuera?» ${ }^{22}$. Es decir, el concepto de 'cercar' para Saadiá significa que los asuntos, la situación o el estado en que se encuentra dicho hombre son los que Dios encierra y, en cambio, el hombre queda fuera, mientras que para Ibn Ezrá este queda dentro. Sin embargo, la mención de la explicación de Saadiá citada por Ibn Ezrá no coincide con el sentido que el gaón da al versículo. Para el Gaón, Jb 3,23 presenta a un hombre desconcertado porque no comprende la situación que está viviendo, debido a que Dios se la ha ocultado y con él

\footnotetext{
${ }^{19}$ Ibn Ezrá está reflejando aquí una tradición literaria hispano-hebrea que tiende a identificar estos nombres bíblicos y que podemos encontrar en autores como Dunaš ben Labrat; vid. G. D. Cohen, «Esau as Symbol in Early Medieval Thought», en A. Altmann (ed.), Jewish Medieval and Renaissance Studies, Cambridge 1967, págs. 19-48.

${ }^{20}$ KafaH, págs. 23-24 y Theodicy, págs. 151-152.

${ }^{21}$ Com.Job, págs. 14* y 34 de la traducción. En su primer comentario a Gé 7,16, explica que la acción de cerrar en relación con Dios tiene una connotación positiva en ese caso, pero no es así en $\mathrm{Jb} 3,23$ y Jb 12,14, donde tiene un sentido negativo «como lo demuestra el comienzo del

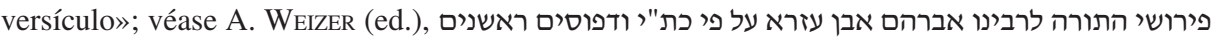
עם מבוא, ביאורים, ציוני מקורות ומקבילות, Jerusalem 1976, vol. I, pág. 40. Es decir, que la expresión «Dios cercó» tiene un sentido negativo como «el hombre cuyo camino está oculto» y, de la misma manera, «si encierra a alguno» $(\mathrm{Jb} 12,14)$ tiene una connotación negativa como la expresión que aparece en la primera parte de este mismo versículo: «si destruye».

${ }^{22}$ KafaH, págs. 43-45 y Theodicy, págs. 181-182. 
parece identificarse el propio Job porque tampoco este conoce la razón de sus sufrimientos. Es posible que Ibn Ezrá no tuviera delante la traducción de Saadiá a este versículo y por eso cita una opinión que no se corresponde exactamente con la interpretación del Gaón.

En su comentario a Jb 8,14, Ibn Ezrá critica la interpretación de Saadiá Gaón de la palabra חיקוֹ con el significado de חבל השמש 'hilillo de sol'23. Saadiá tradujo este versículo de la siguiente manera: «cuya confianza es un hilillo de sol y cuya seguridad es una casa de araña» y en su comentario explicó que la palabra ب̣ es un hápax que tiene un significado similar a una tela de araña ${ }^{24}$. Probablemente estaba considerando el paralelismo de significados entre las dos partes del versículo al hacer dicha afirmación.

Ibn Ezrá rechaza esta interpretación, porque, según él, la palabra יָָ está

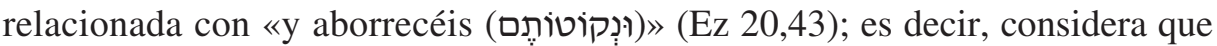
יקוֹ es de una raíz hebrea que tiene el significado de 'aborrecer', 'tener horror a algo'. En lugar de optar por el paralelismo de significados, que es un método muy habitual en la exégesis de Ibn Ezrá, en este caso ha preferido buscar un versículo en el que aparece la misma raíz. Es posible que Ibn Ezrá estuviera influido en este caso por Yehudá Hayyuy, según el cual la palabra ग̦ es de la raíz קוט ${ }^{25}$. Según la interpretación de Ibn Ezrá, el versículo significa que aquel que se olvida de Dios aborrece y desprecia aquello en lo que puede confiar o apoyarse.

A propósito de la queja de Job a sus compañeros en la que afirma que «ya van diez veces que me ultrajáis»(Jb 19,3), Saadiá Gaón interpretó que el número 'diez' hace referencia a los discursos que se habían pronunciado hasta ese momento; sin embargo, él mismo era consciente de que hasta el capítulo 19 sólo encontramos dos discursos de Elifaz, dos de Bildad y uno de Sofar. Para justificar la cifra diez, Saadiá incluyó los cinco discursos de Job y explicó que la razón de contabilizarlos es que, cuando una persona está enfadada porque

${ }^{23}$ Com.Job, págs. $25 *$ y 79.

${ }^{24}$ KAFAH, págs. 67-68 y Theodicy, pág. 216. Kafah explica que la expresión 'hilillo de sol' se refiere a una brizna muy fina hecha por una araña que sólo se ve cuando la luz del sol brilla en ella. L. E. Goodman traduce el texto de Saadiá como 'a gossamer's thread' basándose en el significado de la palabra «gossamer» que aparece en el Oxford English Dictionary: «a fine filmy substance, consisting of cobwebs spun by small spiders, which is seen floating in the air in calm weather, esp. in autumn»; véase Theodicy, págs. 219-220.

${ }^{25}$ Two Treatises on Verbs containing Feeble and Double Letters by R. Jehuda Hayug of Fez. Translated into Hebrew from the original Arabic by R. Moseh Gikatilia of Cordoba, to which is added the Treatise on Punctuation by the same Author translated by Aben Ezrá. Edición y traducción inglesa por W. Nutt, London-Berlin 1870, pág. 55. 
algo que ha oído no le ha gustado, se siente irritada primero cuando se lo dicen y después cuando responde a lo que le han dicho, es decir, dos veces, que, en este caso, hacen un total de diez discursos ${ }^{26}$. Ibn Ezrá rechaza esta explicación y propone considerar el diez como un número redondo que indica una gran cantidad y no hay que interpretarlo en sentido literal como un número exacto ${ }^{27}$.

Saadiá Gaón interpreta los versículos 2, 3 y 4 del capítulo 37 como la manifestación del poder de Dios en la tormenta y parece entender que la luz mencionada en el versículo 3 en la expresión «su luz (אiֹרו) alcanza los extremos de la tierra» se refiere a la gloria divina que llega a todas las regiones de la tierra ${ }^{28}$. Probablemente, la interpretación de Saadiá trataba de justificar que el pronombre personal sufijado a la palabra אic es una referencia a Dios. Ibn Ezrá rechaza este sentido porque considera que el versículo no puede referirse a Dios debido a que no tiene relación con el anterior y el posterior; es decir, que según él los versículos 2 y 4 sí se refieren a Dios, pero la luz del versículo 3 es para él la del relámpago, no la gloria divina ${ }^{29}$. Según Ibn Ezrá el versículo significa «bajo todo el cielo lo empapa y la luz del relámpago alcanza los extremos de la tierra». Es decir, Ibn Ezrá interpreta el versículo en el contexto de los fenómenos meteorológicos asociados a la tormenta y busca una explicación más racional y literal para la palabra 'luz', mientras que Saadiá enfatiza el punto de vista de la teofanía en todo el pasaje, porque este es uno de los asuntos centrales de su comentario a Job. Es posible, además, que Ibn Ezrá se dejara influir por la interpretación de Yoná ibn Yanạ quien, en su explicación de este versículo, da a entender que la luz mencionada es el relámpago ${ }^{30}$.

El versículo Jb 38,24 corresponde al discurso que Dios dirige a Job y en él pregunta: «ide qué manera se distribuye la luz y el solano se extiende por la tierra?» Saadiá Gaón tradujo así el versículo: «¿de qué manera se parte la luz o

\footnotetext{
${ }^{26}$ KAFAH, pág. 114 y Theodicy, pág. 287. También Raší y Rašbam interpretaron este número en referencia a los discursos de los compañeros y a las respuestas de Job; véase Peruš, $i b$. y para el comentario de Rašbam, véase S. JAPHET (ed.), The Commentary of R. Samuel ben Meir (Rashbam) on the Book of Job (en hebreo), Jerusalem 2000, pág. 386.

${ }^{27}$ Com.Job, págs. 39* y 146.

${ }^{28}$ KAFAH, pág. 180 y Theodicy, pág. 376 y nota en la página 379.

${ }^{29}$ Com.Job, págs. $72 *$ y 273.

${ }^{30}$ Sepher Haschoraschim: Wurzelwörterbuch der hebräischen Sprache von Abulwalîd Merwân Ibn Ganah (R. Jona). Aus dem Arabischen in's Hebräische übersetz von Jehuda ibn Tibbon und mit Registern und einem Anhange, Textberichtigungen zum Sepher Harikma, versehen von W. Bacher, Berlin 1896 (en adelante Šorašim), sub voce עקב.
} 
se extienden sus rayos por la tierra?» ${ }^{31}$ y más adelante explicó que se trata de «una descripción de la emanación de la luz cuando atraviesa la columna cónica de la oscuridad, que es la sombra de la tierra, y que se levanta con forma de cono» ${ }^{32}$.

Ibn Ezrá cita la interpretación de Saadiá de la siguiente manera: «el Gaón Rabí Saadiá interpretó: ¿de qué manera se coloca la luz sobre una zona que hay en la tierra que es todo luz, excepto un día, que es todo lo contrario?» y después añade: «aunque sus palabras son correctas, no se pueden hacer esas deducciones del significado de estos versículos» ${ }^{33}$. Es decir, Ibn Ezrá considera que la interpretación de Saadiá es una referencia a la proyección de la luz del Sol sobre la Tierra, dependiendo de la posición de aquel con respecto al hemisferio norte o sur y admite que esta observación es correcta; sin embargo, rechaza el hecho de que del versículo bíblico se pueda extraer este tipo de conclusiones. Da la impresión de que Ibn Ezrá prefiere mantener el sentido literal del versículo, considerar que la luz mencionada es simplemente un fenómeno natural difícil de explicar y alejarse de digresiones de carácter cosmológico o metafísico que poco o nada tienen que ver con el discurso. No obstante, es sorprendente que Ibn Ezrá, que en muchos de sus comentarios utiliza el texto bíblico como excusa para introducir este tipo de disquisiciones y explicaciones científicas, sea el que critique a Saadiá un método exegético que él emplea con asiduidad.

En resumen, en las seis ocasiones en que Abraham ibn Ezrá cita a Saadiá por su propio nombre en su comentario a Job, su objetivo es manifestar claramente su oposición a las interpretaciones del Gaón. En estos casos Ibn Ezrá quiere mantenerse más cercano al significado literal de los versículos bíblicos, prefiere encontrar otros pasajes para apoyar sus interpretaciones y trata de evitar observaciones de carácter metafísico o científico que se apartan del sentido literal del texto.

El análisis de estas citas demuestra claramente que Ibn Ezrá conoció el comentario de Saadiá al libro de Job; sin embargo, la forma de citar sus palabras, resumiendo en algunos casos sus explicaciones, tergiversando sus palabras en parte o mencionando de manera diferente las interpretaciones del gaón también demuestran que Ibn Ezrá no tenía delante el comentario de aquel y es posible que lo citara de memoria o básandose en notas que el propio Ibn Ezrá podría haber tomado.

\footnotetext{
${ }^{31}$ KafaH, pág. 188 y Theodicy, pág. 385.

${ }^{32}$ KafaH, pág. 197 y Theodicy, pág. 396.

${ }^{33}$ Com.Job, págs. 77*-78* y 290-291.
} 


\section{Opiniones de SaAdiá GaÓn como citas anónimas}

Como es habitual en sus comentarios, Ibn Ezrá cita opiniones de otros autores יש o יש מפרשים para referirse a ellos. Algunas de estas citas anónimas que aparecen en su comentario a Job coinciden con las interpretaciones de Saadiá Gaón y demuestran que Ibn Ezrá se está refiriendo a él, aunque no lo cite por su propio nombre.

En su comentario a Jb 5,7, Ibn Ezrá menciona varias explicaciones de la expresión בְנֵּ רֶשֶׁ, literalmente 'hijos de las chispas' o 'hijos de las llamas'. Una de ellas sostiene que son «los destinados a estar en la gehena, que son los que se muestran orgullosos en este mundo» ${ }^{34}$. Esta explicación coincide con la de Saadiá Gaón que interpretó בִּנְ רֶשֶ así: «son los que están destinados a las llamas, los engreídos que sólo piensan en sí mismos, son unos jactanciosos y se alzan como los pájaros» ${ }^{35}$. Ibn Ezrá rechaza esta interpretación utilizando uno de los típicos juegos de palabras habituales en sus críticas a otros autores: «esta interpretación no tiene chispa, es más bien fría».

Según las explicaciones de Ibn Ezrá, el versículo Jb 15,24 significa lo siguiente: «la angustia y la inquietud le tienen aterrorizado, le atacan como un rey dispuesto al combate». Explica que la palabra מלחמה significa 'guerra', 'batalla', 'combate' y que es un hápax; además añade: «algunos dicen que significa que le rodearon las angustias, como el círculo de la esfera que rodea a la pelota (כָדּור), que es la tierra, igual que "como una pelota (פכּדוּר) hacia un país' (Is 22,18)». Esta explicación es la que encontramos en el comentario del propio Saadiá Gaón, que tradujo las palabras bíblicas de la siguiente manera: «como la esfera rodea al globo terrestre». Para justificar una traducción tan alejada del sentido literal, Saadiá explicó

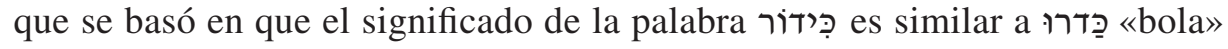
o «pelota», como en Is 22,18, y de aquí dedujo que es una referencia al globo terrestre. Para explicar la relación de significados entre el rey mencionado en el versículo y la esfera que rodea la Tierra, Saadiá argumentó que, si a las estrellas se las denomina «ejército» en la Biblia, entonces a la esfera celestial se la puede llamar «rey»; de esta manera, la metáfora que el texto pone en boca de Elifaz adquiere el siguiente sentido: al malvado le rodean las dificultades, de la misma manera que la esfera rodea la Tierra ${ }^{36}$. Ibn Ezrá, por su parte, rechaza esta

\footnotetext{
${ }^{34}$ Com.Job, págs. $17 *-18$ y 49-50.

${ }^{35}$ KafaH, pág. 50 y Theodicy, pág. 191.

${ }^{36}$ KAFAH, págs. 101-102 y Theodicy, pág. 265.
} 


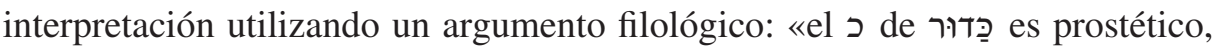

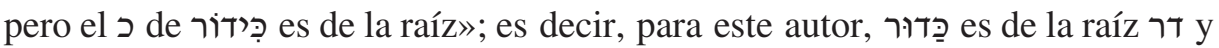

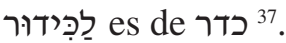

En la respuesta que Job dirige a sus compañeros en el capítulo seis

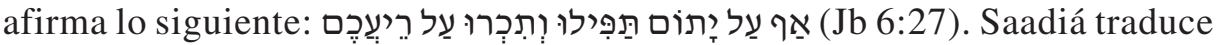
así el versículo: «¿váis a caer sobre un huérfano y celebraréis un banquete por vuestro amigo?» En el propio comentario Saadiá afirma que el término וְתִכְרוּ significa 'celebrar una fiesta' 'preparar un convite' o 'celebrar un

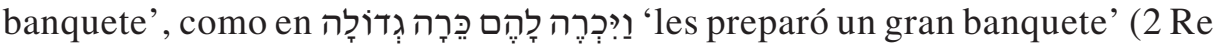
6,23 ) y explica que Job les pregunta a sus compañeros si se han reunido para burlarse de él, comiéndose su carne y celebrando un banquete a su costa ${ }^{38}$. En el comentario de Ibn Ezrá encontramos una explicación muy similar, aunque no aparece atribuida a otros autores, y es la siguiente: «os juntáis para alegraros de la desgracia de vuestro amigo» y lo relaciona también con el caso de 2 Re 6,23. Sin embargo, Ibn Ezrá ofrece otra explicación que le parece más correcta. En su opinión la palabra וְתִ está relacionada con el

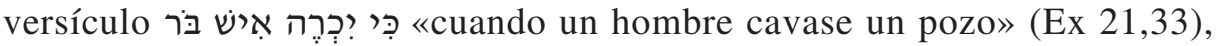
porque en ambos casos la raíz כרה tiene el sentido de 'cavar' o 'excavar'. Ibn Ezrá además justifica este significado argumentando el paralelismo con la primera parte del versículo donde aparece el verbo 'derribar'; es decir, que para él Job se queja ante sus compañeros porque son capaces de derribar a un huérfano y de cavar una fosa o un pozo para que caiga su amigo ${ }^{39}$.

En algunos casos, las citas que Ibn Ezrá atribuye a otros autores aparecen en el comentario de Saadiá, pero no de forma exclusiva, pues también las encontramos en otras fuentes a las que pudo tener acceso Ibn Ezrá, lo cual nos impide concluir que esté citando a Saadiá exclusivamente. Es muy posible que, en estos casos, Ibn Ezrá se esté refiriendo a varios autores, incluyendo al gaón. En su comentario a Jb 34,36, Ibn Ezrá explica que la palabra אִָ se refiere

\footnotetext{
${ }^{37}$ En su Sefat Yéter, Ibn Ezrá explica claramente que la palabra דo pertenece a una raíz biconsonántica, es decir דר , לק , «porque la letra de prolongación no cuenta, de la misma

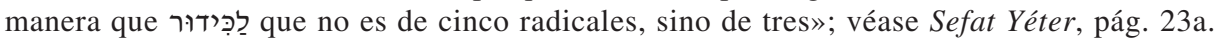
Este es un ejemplo de que la teoría triconsonántica de la raíz hebrea que fue la gran novedad de Hayyuy no fue totalmente aceptada por Ibn Ezrá; sobre este asunto, véase A. SÁEnzBAdillos, «Some Basic Concepts in the Linguistic System of Abraham Ibn Ezra», en Studies in Hebrew and Jewish Languages Presented to Shelomo Morag. Edited by M. Bar-Asher, Jerusalem 1996, págs. $125 *-149 *$ : $145 *$ y sigs.

${ }^{38}$ KaFAH, pág. 60 y Theodicy, pág. 204.

${ }^{39}$ Com.Job, págs. 22*-23* y 68-69. Así también lo interpretó Raší; véase Peruš, ib.
} 
a Dios, aunque señala que en el versículo falta la indicación del vocativo ${ }^{40}$; es decir, para Ibn Ezrá אָ̣ es una invocación a Dios con el sentido de 'Padre mío'. Además añade «algunos dicen que אִָ es como 'deseo' y quiere decir 'mi voluntad'»" ${ }^{41}$; es decir, quienes así lo interpretan consideran que es de la raíz אבה 'desear', 'tener voluntad'. Esta referencia coincide con la traducción

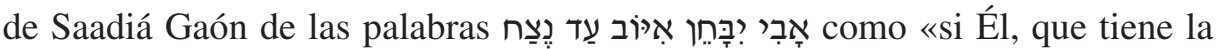
voluntad, desea poner a prueba a Job al máximo» ${ }^{42}$; sin embargo, encontramos interpretaciones similares en el Targum, el Maḥberet de Menahem ben Saruq y en el comentario de Raší a este mismo versículo. El Targum recoge los dos sentidos mencionados y propone la siguiente traducción: «yo deseo que el Padre que está en los cielos ponga a prueba a Job para siempre» ${ }^{43}$. Menahem ben Saruq, por su parte, interpretaba el versículo así: «mi voluntad y mi deseo es que Job sea torturado hasta el fin» ${ }^{44}$. Raší entiende אִָ̣ en el sentido de 'padre', pero sugiere también la posibilidad de interpretarlo con el significado de 'deseo' ${ }^{45}$.

\section{Opiniones de Abraham ibn Ezrá similares a las de SaAdiá Gaón}

A pesar del rechazo a las interpretaciones de Saadiá, son numerosos los casos en los que las explicaciones del propio Ibn Ezrá coinciden con las del Gaón, lo cual demuestra que Ibn Ezrá hizo buen uso del comentario de aquel. A continuación se analizan algunos de estos casos.

\section{Comentarios sobre el léxico}

Ibn Ezrá coincide con Saadiá Gaón en interpretar la palabra הרָ en Jb 3,2 en el sentido de 'nacer' o 'dar a luz', no de 'concebir' o 'ser concebido' como normalmente se traduce. Según ambos autores, el versículo significa «desaparezca el día en que nací y la noche en que se dijo: "Ha sido dado a

\footnotetext{
${ }^{40}$ Se refiere a la ausencia del אחבִי delante de la palabra.

${ }^{41}$ Com.Job, págs. 67* y 255-256.

${ }^{42}$ KAFAH, pág. 171 y THEODICY, pág. 361.

${ }^{43}$ D. M. STEC (ed.), The Text of the Targum of Job. An Introduction and Critical Edition, Leiden-New York-Köln 1994 (en adelante Targum Job), pág. 241*.

${ }^{44}$ Menahem Ben SARUQ, Maḥberet. Edición crítica e introducción de A. Sáenz-Badillos, Granada 1986, pág. 17*.

${ }^{45}$ Véase Peruš, $i b$. 
luz un varón"», y de esta manera se destaca el paralelismo de significados entre ambas partes del versículo ${ }^{46}$. Ambos autores también coinciden en citar el caso de «ella dio a luz (וֵַַ) a Miriam» (1 Cr 4,17) como prueba de su argumentación. La mayoría de comentaristas, tanto antiguos como modernos, por el contrario, interpretan הדָר en el sentido de 'concebir'.

En su primer discurso, Elifaz habla del destino de los seres humanos y

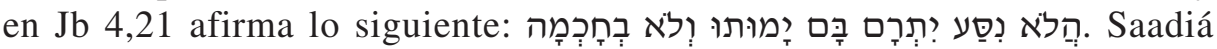
traduce la primera parte del versículo de la siguiente manera: «¿acaso no se llevan sus bienes con ellos?» y en su comentario explica que la palabra ?ְִֶ ? no se refiere a los bienes trascendentales, como la pureza o la rectitud, sino a los de este mundo, tales como la riqueza y la posición social ${ }^{47}$. En el comentario a Ibn Ezrá encontramos la misma explicación; según

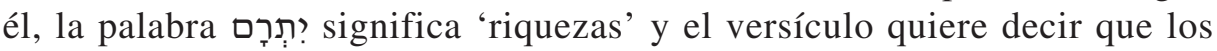
seres humanos pierden sus riquezas cuando se mueren. Para justificar el

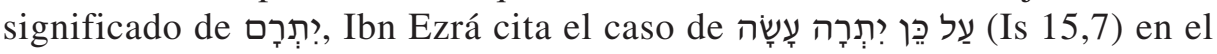

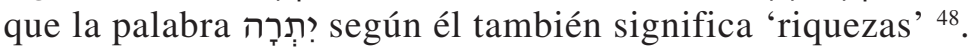

Elifaz, el temanita, comienza su discurso del capítulo 22 con la frase

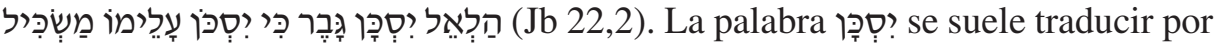
'ser útil', 'ser beneficioso' y así la interpreta buena parte de los comentaristas medievales ${ }^{49}$. Aunque Ibn Ezrá menciona este significado, él se inclina por

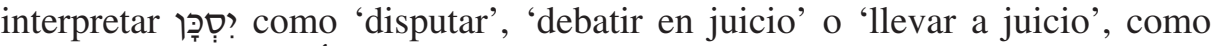
«debate (הַסְּ) con Él y haz las paces» (Jb 22,21) y explica así el sentido del versículo: «¿acaso un hombre puede debatir en juicio con Dios? o ¿puede establecer un debate entre ambos una persona inteligente?» ${ }^{50}$. Esta interpretación coincide con la explicación de Saadiá Gaón de este versículo: «¿acaso alguien está dispuesto a enfrentarse a Dios en un juicio de tal manera que una persona

\footnotetext{
${ }^{46}$ Com.Job, págs. $11 *-12 *$ y 24-25 y KAfAH, pág. 41 y Theodicy, págs. 179 y 182-183.

${ }^{47}$ KafAH, págs. 48-49 y Theodicy, pág. 188.

${ }^{48}$ Com.Job, págs. 16* y 45.

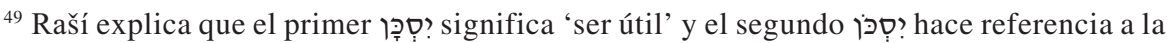
idea de enseñar; él interpreta el versículo así: «¿acaso puede el hombre ser útil a la necesidad y al beneficio del Creador enseñando conocimiento y sabiduría a las demás criaturas?»; véase Peruš, ib. Ibn Yanaḥ también lo interpreta en el sentido de «el que está dirigido y preparado para hacer lo que es útil», relacionando este versículo con Jb 15,3; 22,21; 34,9 y 35,3; véase Šorašim, sub voce סכן. El Targum lo traduce en el sentido de «enseñar»; véase Targum Job , pág. 149* y también lo interpreta así Rašbam; véase JAPHET, The Commentary, pág. 394.

${ }^{50}$ Com.Job, págs. $43 *$ y 168.
} 
inteligente coordine a ambos? Es decir, que se establezca un juez inteligente que escuche lo que digan tanto Dios como el hombre» ${ }^{51}$.

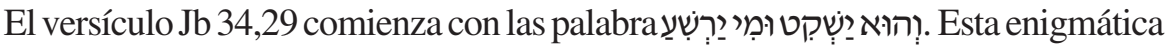
frase, en la que el protagonista de la historia está refiriéndose a Dios, se ha traducido de diversas maneras: «si Él reposa, ¿quién le inquietará?» ${ }^{52}$, «Él justifica, ¿quién puede condenar?» ${ }^{53} \mathrm{O}$ «porque esté quieto, ¿quién podrá condenarlo?» ${ }^{54}$. La palabra

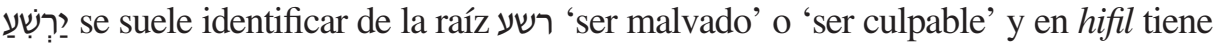
el sentido de 'condenar'; sin embargo, Ibn Ezrá la interpreta de forma diferente, pues

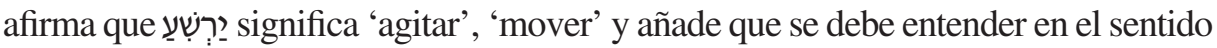

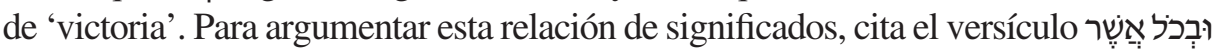

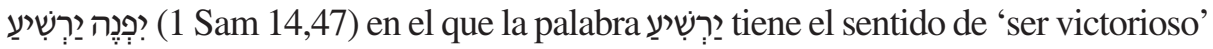
pues se puede traducir como «donde él [Saul] se dirigía, salía victorioso». En su comentario al versículo de Job, Ibn Ezrá justifica la relación entre 'agitarse' y 'ser victorioso' explicando que «en el momento de la victoria los hombres se agitan» ${ }^{55}$. Es posible que, al interpretar la raíz רשע en el sentido de 'moverse', 'agitarse', Ibn Ezrá estuviera pensando en una raíz רעש como resultado de una metátesis entre las letras $ע$ y $w^{56}$. Saadiá Gaón traduce Jb 34,29 de la siguiente manera: «si Él establece una nación, ¿quién puede vencerlos?»; es decir, interpreta el verbo ?ִ en el sentido de 'vencer', 'conquistar', 'dominar' ${ }^{57}$. Parece ser que Ibn Ezrá tomó esta idea de Saadiá Gaón y elaboró su propia explicación para justificarla.

Abraham ibn Ezrá también pudo dejarse influir por Saadiá Gaón en el uso del arameo del Targum para explicar el significado de algunas palabras hebreas, aunque hay que tener en cuenta que otros gramáticos y exegetas anteriores a Ibn Ezrá también siguieron este método. Así, Ibn Ezrá coincide con Saadiá en señalar que la expresión hebrea מִן (Jb 30,5) significa «en medio»,

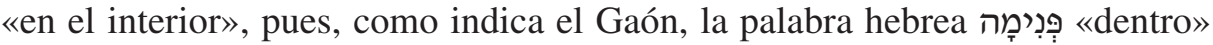
(Lev 10,18) en el Targum a este versículo se traduce por

\footnotetext{
${ }^{51}$ KafAH, pág. 127 y Theodicy, pág. 306.

${ }^{52}$ F. Cantera Burgos-M. Iglesias GonzÁlez, Sagrada Biblia, Madrid 1979, pág. 713.

${ }^{53}$ N. H. Tur-SinaI, The Book of Job. A New Commentary, Jerusalem 1967, pág. 484.

${ }^{54}$ L. Alonso SchöKel - J. L. Sicre Díaz, Job: Comentario teológico y literario, Madrid 1983, pág. 480.

${ }^{55}$ Com.Job, págs. $43 *$ y 168.

${ }^{56}$ La metátesis es un método relativamente habitual en la exégesis de Ibn Ezrá.

${ }^{57}$ KafaH, pág. 170 y Theodicy, pág. 360.

${ }^{58}$ Com.Job, págs. 55* y 213, KAFAH, pág. 151 y Theodicy, pág. 339. Véanse otros ejemplos de la coincidencia entre Ibn Ezrá y Saadiá Gaón en el uso del arameo del Targum en sus comentarios respectivos a $\mathrm{Jb} 30,7$ y 33,21 .
} 
de Jb 30,5, sin embargo, no interpreta מִן en en este sentido, sino que lo traduce por «ante los débiles» ${ }^{59}$. No obstante, otros autores como Menahem ben Saruq o Yoná ibn Yanah también habían recurrido al Targum para interpretar este caso ${ }^{60}$; por lo tanto, no podemos afirmar con total seguridad que Ibn Ezrá esté influido exclusivamente por Saadiá Gaón.

Ibn Ezrá también coincide con Saadiá Gaón en el uso de la lengua del Talmud para explicar algunas palabras bíblicas de difícil interpretación; aunque también en este método, Ibn Ezrá pudo estar influido por otros comentaristas o exegetas anteriores a él ${ }^{61}$.

\section{Teorías científicas y filosóficas}

Como en la mayoría de sus tratados exegéticos, también en su comentario al libro de Job utiliza Ibn Ezrá sus conocimientos científicos en el campo de la astronomía y astrología medievales para interpretar algunos versículos bíblicos.

Ibn Ezrá identifica las estrellas y constelaciones que aparecen en $\mathrm{Jb}$ 9,9 y, a propósito de las 'Cámaras del Sur' dice que «son las estrellas que están al sur de la esfera», es decir, en el hemisferio sur ${ }^{62}$. Para justificar la denominación que reciben estos astros, Ibn Ezrá explica que «debido a que la parte habitada del mundo se encuentra en el hemisferio norte, no se las puede ver, por eso se las llama 'cámaras', como si estuvieran en un lugar escondido» ${ }^{63}$. En el comentario de Saadiá Gaón a este mismo versículo encontramos una explicación muy similar: «Muchas estrellas serían visibles si estuvieramos por debajo de la línea del Ecuador, pero están ocultas para nosotros en el cielo sur; por lo tanto, son como un objeto escondido en una cámara» ${ }^{64}$. Aunque los conocimientos astronómicos los adquirió Ibn Ezrá de otras fuentes, lo que no cabe duda es que en su explicación del nombre de las 'Cámaras del Sur' utilizó la interpretación de Saadiá.

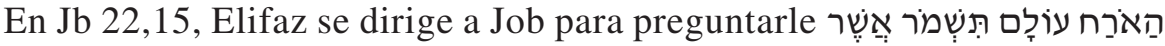
se suele traducir literalmente como 'el camino del mundo' o 'el viejo camino' y así, el sentido de la frase es «¿vas

\footnotetext{
${ }^{59}$ Targum Job, pág. 199*.

${ }^{60}$ Maḥberet, pág. 102* y Šorašim, sub voce ג.

${ }^{61}$ Véanse, por ejemplo, sus comentarios respectivos a Jb 3,7 y 6,6.

${ }^{62}$ Sobre la identificación de estas estrellas, véase G. R. DrIVER, «Two Astronomical Passages in the OT», JTS 7 (1956) 1-11 y GómEZ ArANDA, «Aspectos científicos», págs. 90-94.

${ }^{63}$ Com.Job, págs. $25 *-26$ y 83.

${ }^{64}$ KafaH, págs. 70-71 y Theodicy, pág. 222.
} 
a seguir el camino del mundo (o el viejo camino) que pisaron hombres

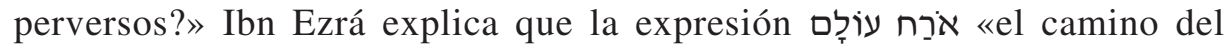
mundo» se refiere «a los que dicen que el mundo ha sido siempre así y que no hay nada nuevo» ${ }^{65}$; es decir, se trata de una alusión a quienes, siguiendo las teorías de Aristóteles, pensaban que el mundo era eterno. Saadiá Gaón traduce este versículo de la siguiente manera: «¿vas a mantener la doctrina de los que defienden la eternidad del mundo, que siguen los malvados?» ${ }^{66}$ No cabe duda de que Ibn Ezrá está influido por la traducción de Saadiá Gaón al escribir su comentario.

La teoría filosófica de que la materia está compuesta de cuatro elementos -agua, aire, tierra y fuego- está muy presente en la exégesis de Abraham ibn Ezrá, que trata, en varias ocasiones, de encontrar versículos que apoyen la presencia de esta idea en la Biblia ${ }^{67}$. También Saadiá Gaón se esforzó por argumentar que los cuatro elementos de la materia están presentes de manera alegórica en los primeros versículos del Génesis ${ }^{68}$. Ibn Ezrá encuentra una alusión a esta teoría en los versículos: «Él observa hasta los confines de la tierra y ve lo que hay bajo los cielos, al dar peso al viento y definir la medida de las aguas» (Jb 28,24-25). La aparición de las palabras 'tierra', 'cielos' (= fuego) ${ }^{69}$, 'viento' (= aire) y 'agua' es el motivo de que Ibn Ezrá interprete que lo que quiere decir Job al utilizar estas palabras es que los seres humanos son incapaces de comprender la naturaleza de estos cuatro elementos y que solamente Dios, que es el que los ha creado, puede entender lo que significan. Saadiá Gaón también encontró una alusión a esta teoría en estos mismos versículos y así lo afirma en su comentario: «Menciona los cielos, la tierra, el viento y el agua, puesto que son los cuatro elementos. El hombre no puede entender cómo se constituyen y cómo se establecen, sino que se atribuye a Él, ensalzado y exaltado, el conocimiento

\footnotetext{
${ }^{65}$ Com.Job, págs. $44 *$ y 170.

${ }^{66}$ KAFAH, pág. 129 y Theodicy, págs. 307 y 309-310.

${ }^{67}$ Sobre este asunto, véase M. GómEz Aranda, «The Meaning of Qohelet According to Ibn Ezra's Scientific Explanations», Aleph 6 (2006), 339-370: 347-348.

${ }^{68}$ M.Zucker (ed.), Saadya's Commentary on Genesis, New York 1984, págs. 27-30 y 209-216 de la traducción hebrea.

${ }^{69}$ Sobre la teoría de los cuatro elementos en el pensamiento de Ibn Ezrá, véase su comentario a Sal 148, donde indica expresamente que el fuego son los cielos, y también Yesod Morá 1,6; véase Abraham Iвn Ezra, Yesod Mora ve-Sod Torah: The Foundation of Piety and the Secret of the Torah. An Annotated Critical Edition by J. Cohen in collaboration with U. Simon (en hebreo), Ramat Gan 2002, págs. 78-80 y también J. CoHEN, הגותו הפילוסופית של ר' אברהם אבן עזרא, Jerusalem 1996, pág. 74.
} 
de sus acciones y su funcionamiento» ${ }^{70}$. No cabe duda de que, una vez más, Ibn Ezrá está siguiendo las explicaciones de Saadiá Gaón.

\section{Las introducciones a ambos comentarios}

Una de las principales características de los comentarios bíblicos de Saadiá Gaón es que suelen estar precedidos de una larga introducción en la que el autor expone las principales ideas del libro bíblico que se propone comentar y los objetivos de su propia exégesis ${ }^{71}$. La costumbre de incluir introducciones a los comentarios bíblicos, muy habitual en nuestro tiempo, no era tan frecuente en la época medieval, aunque el estilo de Saadiá Gaón marcó un precedente que fue seguido por otros autores, sobre todo en Sefarad ${ }^{72}$. Ibn Ezrá también continúa esta tradición de escribir introducciones a sus comentarios con un estilo muy similar al del Gaón. Varios puntos en común se pueden encontrar en las introducciones de sus respectivos comentarios a Job ${ }^{73}$.

En su introducción al comentario de Job, Ibn Ezrá trata el problemático asunto de las desgracias que les suceden a los justos y explica que existen varios tipos de sufrimientos, algunos de los cuales tienen como objetivo servir de corrección y enseñanza; pone como ejemplos el caso del padre que castiga a su hijo por una mala acción que este ha cometido y de esta manera le corrige, o el del médico que receta medicinas a los enfermos con el fin de curarles. También añade que, a veces, los seres humanos reciben sufrimientos que tienen como objetivo el de recompensarles posteriormente. En el caso concreto de Job, Ibn Ezrá afirma que sus sufrimientos no fueron un castigo por sus pecados.

Por el contenido del comentario llegamos a la conclusión de que lo que Ibn Ezrá quiso decir es que los seres humanos somos incapaces de entender por qué

\footnotetext{
${ }^{70}$ KafaH, pág. 146 y Theodicy, pág. 331-332.

${ }^{71}$ E. I. J. Rosenthal, «Saadya Gaon: An Appreciation of his Biblical Exegesis», Bulletin of the John Rylands Library 27 (1942), págs. 168-178: 170-174.

${ }^{72}$ Sobre este asunto, vid. H. Ben Shammal, «Saadia's Introduction to Daniel: Prophetic Calculation of the End of Days vs. Astrological and Magical Speculation», Aleph 4 (2004), 1187; ID. «New and Old: Saadya's Two Introductions to His Translation of the Pentateuch» (en hebreo), Tarbiz 69 (2000), id. 199-210 e ID. «Saadya's Introduction to Isaiah as an Introduction to the Books of the Prophets» (en hebreo), Tarbiz 60 (1991), 371-404; M. Sokolov, «Saadiah Gaon's Prolegomenon to Psalms», PAAJR 51 (1984), 131-174; A. Segal, «Zerahia Hen's Introduction to his Commentary on the Book of Job» (en hebreo), Daat 56 (2005), 83-100; y M. Rosenthal, «The Haqdamah of Immanuel of Rome to the Book of Ruth», en D. R. Blumenthal (ed.), Approaches to Judaism in Medieval Times, Chico 1985, págs. 169-185.

${ }^{73}$ Com.Job, págs. 5*-6*, 4-6, KAFAH, págs. 9-22 y Theodicy págs.123-132.
} 
Job recibió tantas desgracias, y que este es uno de los grandes misterios de la Providencia Divina.

Estas mismas ideas aparecen en la introducción de Saadiá Gaón. También este autor distingue varios tipos de sufrimientos en los seres humanos, aunque se extiende en los detalles de cada uno de ellos de forma más exhaustiva. Los mismos ejemplos que usa Ibn Ezrá para ilustrar de qué manera benefician los sufrimientos a los seres humanos también aparecen en el texto de Saadiá. Da la impresión de que lo que hizo Ibn Ezrá fue resumir los argumentos del Gaón sobre este asunto.

Ibn Ezrá termina su introducción explicando su intención de dividir el comentario en dos partes: en la primera, analizará las palabras difíciles del texto bíblico y aclarará sus significados siguiendo las normas de la gramática hebrea; en la segunda, explicará el significado del libro de Job en su conjunto, analizando el contexto y las relaciones entre los versículos y los discursos de los personajes.

Saadiá Gaón también concluye su introducción mostrando su intención de aclarar «todo aquello que requiera una explicación» utilizando el apoyo de otros pasajes de la Escritura. También divide el comentario en dos partes: en la primera, se centra en las explicaciones lingüísticas de las palabras más difíciles y, en la segunda, analiza cada uno de los discursos como unidades literarias que contribuyen al sentido global del libro. En resumen, el comentario de Saadiá Gaón al libro de Job también influyó en la estructura del de Ibn Ezrá. Este autor coincide con el Gaón en incluir una introducción a su comentario en la que reflexiona, como aquel, sobre los tipos de sufrimientos de los seres humanos y utiliza los mismos ejemplos que aquel para ilustrar sus argumentos. En la exposición de sus objetivos e intenciones y en la organización de sus explicaciones, Ibn Ezrá también se deja influir por el estilo del Gaón.

\section{CONCLUSIONES}

Del análisis de las coincidencias y similitudes entre los comentarios de Saadiá Gaón e Ibn Ezrá al libro de Job podemos extraer varias conclusiones.

Siempre que Ibn Ezrá cita a Saadiá en este comentario tiene como objetivo criticar sus interpretaciones porque considera que, en esos casos concretos, las opiniones del Gaón se alejan bastante del significado literal del texto bíblico. En algunas de estas citas las palabras que Ibn Ezrá atribuye al Gaón no coinciden exactamente con el texto de este, lo que demuestra que, en algún caso, Ibn Ezrá ha resumido el discurso de aquel; pero en otras ocasiones da la impresión de que ha tergiversado sus palabras porque quizá no tenía delante el comentario del Gaón. 
Aunque no aparece citado por su nombre, las interpretaciones de Saadiá coinciden con las opiniones atribuidas por Ibn Ezrá a otros autores. Es posible que, en algunos de estos casos, no aparezca el nombre propio del gaón debido a que sus opiniones no son exclusivas, sino que también las pudo encontrar Ibn Ezrá en las obras de otros exegetas y comentaristas medievales.

Las coincidencias entre las propias explicaciones de Ibn Ezrá al texto de Job y las del Gaón demuestran que Saadiá influyó en aquel en las explicaciones lexicográficas, en el uso del arameo y del hebreo rabínico para dilucidar el sentido de algunas palabras difíciles de entender y en establecer relaciones entre el texto bíblico y las teorías astronómicas y filosóficas de su época.

Finalmente, la comparación entre las introducciones de ambos autores a sus comentarios respectivos demuestran que Saadiá también influyó en el estilo, en los objetivos, en los temas tratados y en la estructura del comentario de Ibn Ezrá.

\section{RESUMEN}

El comentario de Abraham ibn Ezrá al libro de Job está claramente influído por el de Saadiá Gaón. En sus explicaciones, Ibn Ezrá siempre cita las interpretaciones de Saadiá para rechazarlas; sin embargo, algunas de las opiniones atribuídas por Ibn Ezrá a «otros comentaristas» aparecen en la obra del Gaón. Algunas de las propias opiniones de Ibn Ezrá son similares a las de aquél, aunque en estos casos Ibn Ezrá no menciona su fuente. Además existen similitudes entre las introducciones a los comentarios de ambos autores. La exégesis de Saadiá Gaón sobre el libro de Job influyó en el estilo de Ibn Ezrá, en sus perspectivas filológicas y filosóficas y en la propia estructura de su comentario.

Palabras clave: Abraham ibn Ezrá, Saadiá Gaón, exégesis bíblica, Job.

\section{SUMMARY}

Abraham ibn Ezra's commentary on the book of Job is clearly influenced by that of Saadia Gaon. In his explanations, Ibn Ezra always quotes Saadia Gaon's interpretations in order to reject them. However, some of the opinions attributed to "other commentators" by Ibn Ezra are found in Saadia Gaon's work. Some of Ibn Ezra's own explanations are similar to those of the gaon, although in these cases, Ibn Ezra does not mention his source. In addition, similarities between the introductions to the commentaries on Job of these two scholars can be found. Saadia Gaon's exegesis on the book of Job influenced on Ibn Ezra's style, on his philological and philosophical approaches, and on the structure of his commentary.

Keywords: Abraham ibn Ezra, Saadia Gaon, Biblical Exegesis, Job. 